\title{
Combined right atrial and ventricular reduction operation: Case report of unrolling-rolling of the right ventricle to preserve ventricular muscle orientation
}

Hsi-Yu Yu, MD, ${ }^{a}$ Yih-Sharng Chen, MD, ${ }^{a}$ Wen-Yih Tseng, MD, PhD, ${ }^{\mathrm{b}}$ and Fang-Yue Lin, MD, PhD, ${ }^{a}$ Taipei, Taiwan

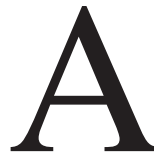

28-year-old man was noted to have had cardiomegaly for years and was sent to the hospital because of progressive congestive heart failure. Chest radiography showed marked cardiomegaly with a cardiothoracic ratio of approximately 1.0 (Figure 1). Echocardiography showed an extremely dilated tricuspid valve anulus and regurgitation, as well as a huge right atrium and ventricle with a competent pulmonary valve. Pulmonary artery pressure was estimated at $35 \mathrm{~mm} \mathrm{Hg}$, and central venous pressure was measured at $16 \mathrm{~mm}$ $\mathrm{Hg}$. Cine magnetic resonance imaging (MRI) study revealed severe tricuspid regurgitation with incompetent leaflets and paradoxical motion of interventricular septum during the cardiac cycle

From the Department of Surgery, ${ }^{\mathrm{a}}$ Department of Radiology, ${ }^{\mathrm{b}}$ National Taiwan University Hospital, Taipei, Taiwan.

Received for publication Jan 4, 2002; accepted for publication Feb 16, 2002.

Address for reprints: Fang-Yue Lin, MD, Department of Surgery, National Taiwan University Hospital, No.7, Chung-Shan South Rd, Taipei 100, Taiwan (E-mail address: fylin@ha.mc.ntu.edu.tw).

J Thorac Cardiovasc Surg 2002;124:1045-7

Copyright $\odot 2002$ by The American Association for Thoracic Surgery $0022-5223 / 2002 \$ 35.00+0 \quad \mathbf{1 2 / 5 4 / 1 2 4 2 4 1}$

doi: $10.1067 / \mathrm{mtc} .2002 .124241$
(Figure 2). Right ventricular (RV) size was $897 \mathrm{~mL}$, and right atrial size was $1930 \mathrm{~mL}$ at end-diastolic phase, as determined on the basis of MRI image calculation. RV biopsy was performed to rule out arrhythmogenic RV dysplasia. Under the impression of congenital tricuspid valve regurgitation caused by annular dilation ${ }^{1}$ and severely dilated right ventricle and atrium, a combined right atrial and ventricular reduction operation (CRAVRO) was performed under cardiopulmonary bypass without aortic clamping.

After direct bicaval cannulation, the right atrium was opened wide across the tricuspid anulus to check the pathologic condition of the tricuspid valve. Its leaflets appeared hypoplastic and its chordae appeared retracted, especially at the septal side, but without downward displacement of the anulus. The right coronary artery was mobilized to the crux of the heart. The cutting edge of the RV free wall went from the tricuspid anulus to the RV outflow tract to the heart apex (Figure 3), moving $2 \mathrm{~cm}$ right to the margin of the interventricular septum, and an $8 \times 15-\mathrm{cm}^{2}$ right myocardial mass was excised. Then the opened parts were sutured with 3-0 polypropylene sutures (Ethicon Inc, Somerville, NJ). The suturing line was performed to preserve the muscle orientation of the right ventricle. Because its native valve leaflet was too small to support effective reconstruction, the anulus was reconstructed to accommodate a 33-mm Hancock II valve (Medtronic Inc, Minneapolis, Minn) as a tricuspid prosthesis. The right atrium was opened from the junction of the superior vena cava, and the right
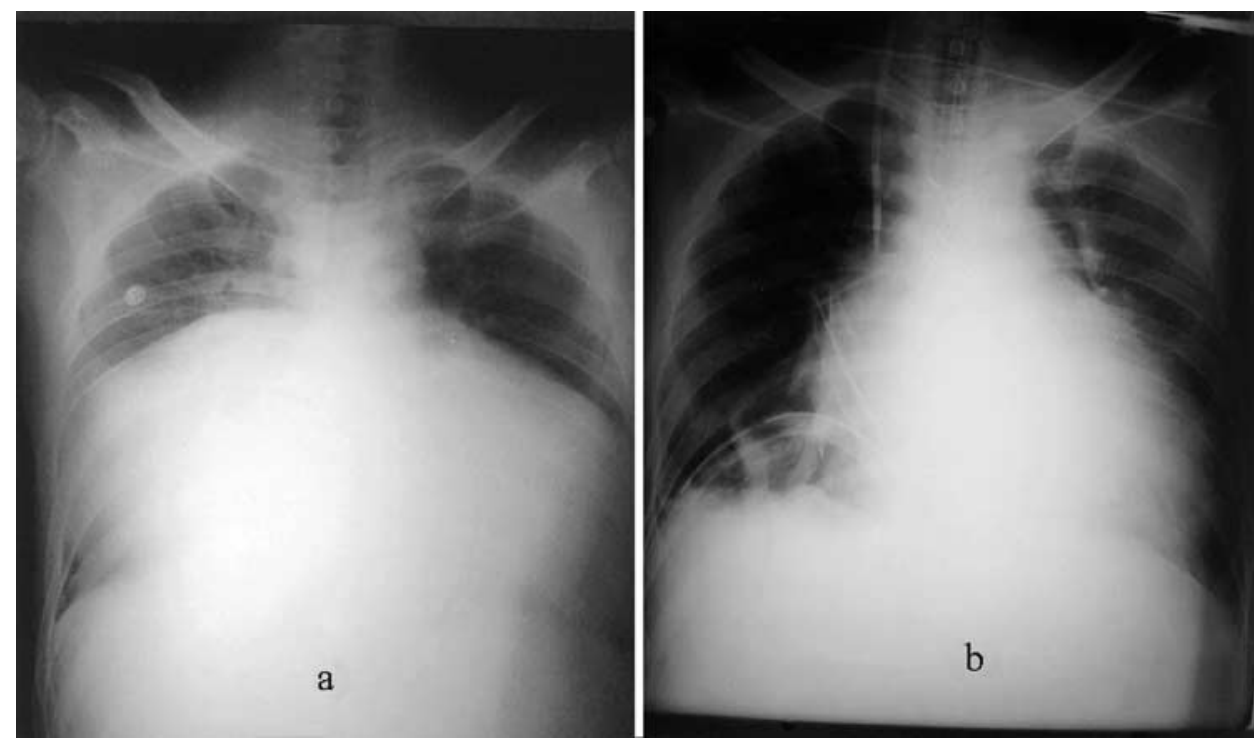

Figure 1. a, Extremely dilated heart before operation with cardiothoracic ratio of approximately 1.0. b, Reduced heart size after operation. 

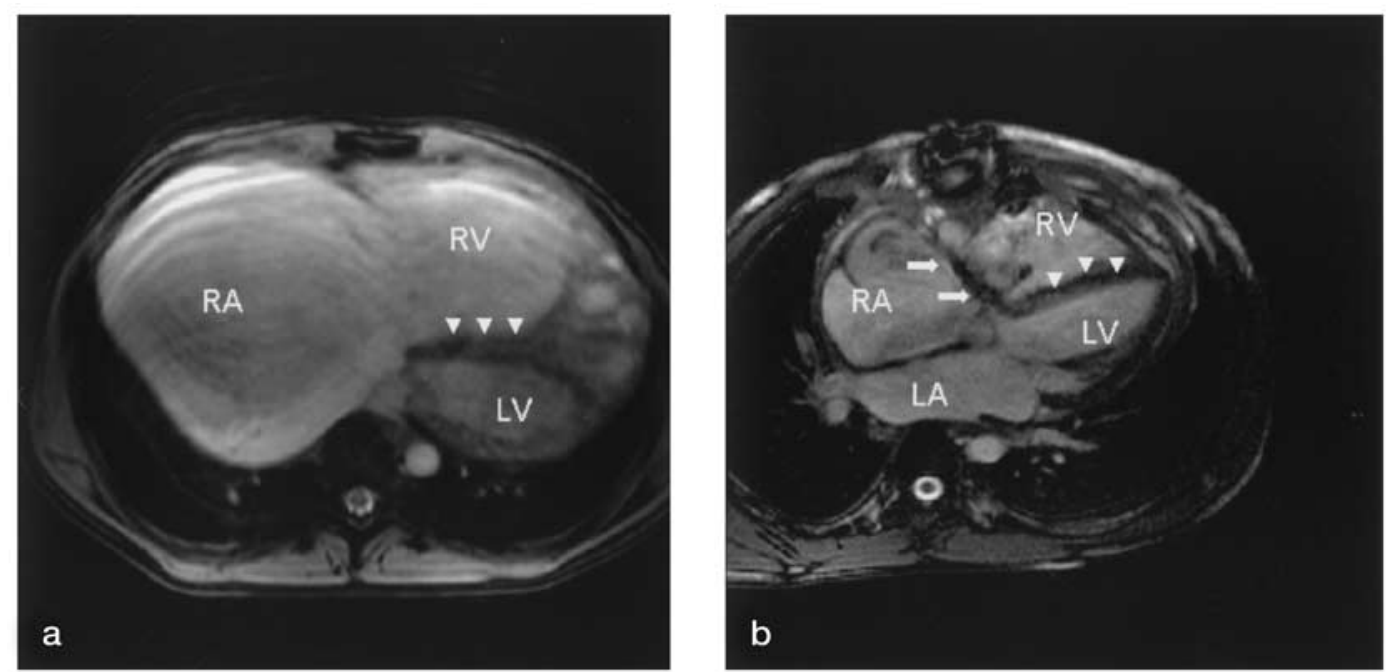

Figure 2. MRI at end-diastolic phase of both preoperative and postoperative stage. a, Huge dilated right ventricle and atrium before operation, with interventricular septum $(\nabla)$ being depressed toward the left ventricle. Tricuspid annular severe dilation can be found. $b$, One month after operation. Both the right atrium and ventricle were reduced in size, with the left ventricle enlarged in size compared with at the preoperative stage. Arrows indicate implanted bioprosthesis. $R A$, Right atrium; $R V$, right ventricle; $L V$, left ventricle.

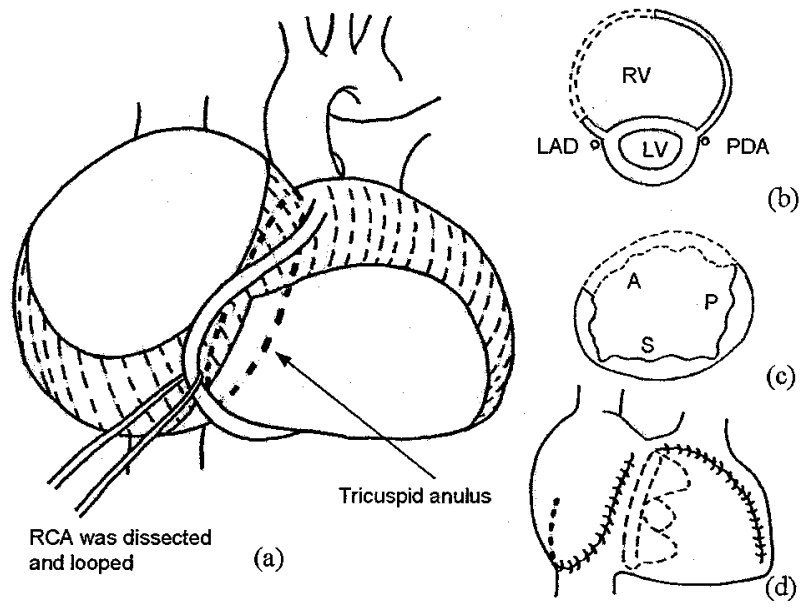

Figure 3. a, The right coronary artery was dissected and looped away from the atrioventricular groove. Dashed area of the right ventricle and right atrium were resected. $R C A$, Right coronary artery. $b$, Transverse section of right and left ventricle perpendicular to the long axis of the left ventricle. The bulging anterior wall of the right ventricle (dashed line) was resected. $R V$, Right ventricle; $L V$, left ventricle; $L A D$, left anterior descending artery; PDA, posterior descending artery. c, Nearly the total anterior leaflet (dashed line) of the tricuspid valve with its anulus was resected. $A$, Anterior leaflet; $P$, posterior leaflet; $S$, septal leaflet. d, The right ventricle and atrium were sutured back with 3-0 Prolene continuous sutures (Ethicon, Inc, Somerville, NJ) according to the myocardial fiber orientation. A Hancock II xenograft was implanted at the tricuspid site. The right coronary artery was shortened, and end-to-end anastomosis was performed (not shown). atrium was opened with preservation of the sinoatrial nodal branch along the atrioventricular groove to the junction of the inferior vena cava and right atrium. Then the cutting edge went backward and upward along the interatrial groove to the point neighboring the right inferior pulmonary vein. An $8 \times 11-\mathrm{cm}^{2}$ right atrial muscle was excised, with the dome part of the right atrium centered on the sinoatrial node preserved. Then the cutting edge was sutured with 3-0 polypropylene sutures. The redundant right coronary artery was shortened with end-to-end anastomosis to resume its flow to its distal part. The patient was weaned off cardiopulmonary bypass without difficulty. He was discharged 10 days after the operation and followed up at the outpatient clinic. He was in New York Heart Association class I 2 months after the operation without ascites or leg edema and with normal liver function. Right atrial and RV sizes were $520 \mathrm{~mL}$ and $242 \mathrm{~mL}$, respectively, as determined by means of MRI image calculation. RV and left ventricular (LV) ejection fraction were $31 \%$ and $44 \%$, respectively, as determined by means of a radionuclide study.

\section{Discussion}

The idea of CRAVRO was based on the concept that the LV and $\mathrm{RV}$ myocardium can be regarded as a continuous band, ${ }^{2}$ which can be unrolled from the interventricular septum to the RV free wall, to the LV free wall, to the descending limb of the left ventricle, and finally to the ascending limb of the left ventricle. Yoshii and associates $^{3}$ reported a partial right ventriculectomy performed in a case of Uhl disease. The triangular resection described in their procedure produced interruption of the RV muscle, which might decrease the contractile force. For our procedure, the semilunar resection of the partial right ventricle, according to the unrollingrolling theory mentioned above, preserved the maximal myocar- 
dial continuity and hence maximal contractility, especially at the inflow part of the right ventricle.

Another key issue in CRAVRO is the reduction of the tricuspid anulus. In LV partial ventriculectomy (the Batista operation), it is almost impossible to perform annular resection, and the persistent dilated atrioventricular anulus would distort the valve geometry and increase regurgitation. The CRAVRO can reduce the size of the tricuspid anulus to normal because coronary vessels can be looped away, and no major accompanying cardiac vein is present in the right atrioventricular groove. ${ }^{4}$ In case the anatomy of the tricuspid valve is still in good condition, leaflet transposition with papillary muscle reimplantation after anulus resection might be performed, as described by Yoshii and associates. ${ }^{3}$

\section{References}

1. Dearani JA, Danielson GK. Congenital Heart Surgery Nomenclature and Database Project: Ebstein's anomaly and tricuspid valve disease. Ann Thorac Surg. 2000;69:S106-17.

2. Torrent-Guasp F, Ballester M, Buckberg GD, Carreras F, Flotats A, Carrio I, et al. Spatial orientation of the ventricular muscle band: physiologic contribution and surgical implications. J Thorac Cardiovasc Surg. 2001;122:389-92.

3. Yoshii S, Suzuki S, Hosaka S, Osawa H, Takahashi W, Takizawa K, et al. A case of Uhl anomaly treated with one and a half ventricle repair combined with partial right ventriculectomy in infancy. $J$ Thorac Cardiovasc Surg. 2001;122:1026-8.

4. Ruengsakulrach P, Buxton BF. Anatomic and hemodynamic considerations influencing the efficiency of retrograde cardioplegia. Ann Thorac Surg. 2001;71:1389-95. 